\title{
Moderna COVID-19 mRNA Vaccine and its Observed Cardiac Side Effects in Adolescent and Children
}

\author{
Sohail Rao ${ }^{1,2 *}$, Caitlin White ${ }^{2}$ and Manish Singh ${ }^{3}$ \\ ${ }^{1}$ Executive Vice President, DHR Health, 5501 S. McColl Road, Edinburg, Texas 78539, and President \& Chief Executive Officer, \\ DHR Health Institute for Research \& Development, USA
}

${ }^{2}$ DHR Health Institute for Research \& Development, 5323 S. McColl Road, Edinburg, Texas, USA

${ }^{3}$ Chief Executive Officer, DHR Health, 5501 S. McColl Road, Edinburg, Texas 78539 and DHR Health Bariatric \& Metabolic Institute, USA

*Corresponding author: Sohail Rao, DHR Health Institute for Research \& Development, 5323 S. McColl Road, Edinburg, Texas, USA

$\begin{array}{lll}\text { ARTICLE INFO } & & \text { ABSTRACT } \\ \text { Received: 幽 November 09, } 2021 & & \text { Keywords: COVID-19; SARS-CoV-2; mRNA Vaccines; Moderna; Pfizer/BioNTech; mRNA- } \\ \text { Published: }: \text { November 16, } 2021 & & \text { 1273; CDC; FDA; EMA; Teen COVE; Kid COVE; ACIP }\end{array}$

Published: 幽 November 16, 2021

Citation: Sohail Rao, Caitlin White, Manish Singh. Moderna COVID-19 mRNA Vaccine and its Observed Cardiac Side Effects in Adolescent and Children. Biomed J Sci \& Tech Res 40(1)-2021. BJSTR. MS.ID.006391.

\section{Introduction}

Infection with SARS-CoV-2 has been the deadliest pandemic in the U.S. infecting over 46 million and claiming the lives of over 749,000 people [1]. To date, the U.S. Food and Drug Administration (FDA) has only approved drugs and/or biological agents for the treatment of patients with COVID-19 under Emergency Use Authorization (EUA). Therefore, the three COVID-19 vaccines that have been approved for use in the U.S. are the most effective tool currently available for the prevention of SAR-CoV-2 infection (Table 1). To date, over 428 million doses of COVID-19 vaccines have been administered resulting in full vaccination of over 193 million people and over 222 million have received at least one dose of these multi-dose vaccines (Table 2). Moderna's COVID-19 vaccine is a lipid nanoparticle-encapsulated mRNA-based vaccine that encodes the prefusion stabilized full-length spike protein of the SARS-CoV-2. Its safety and efficacy was unequivocally established in a Phase 3 clinical trial involving over 30,000 subjects who were randomly assigned in a 1:1 ratio to receive either vaccine or placebo [2]. The vaccine was delivered to established COVID-19 negative volunteers in two-dose protocol 28 days apart. The vaccine was $94.1 \%$ effective in preventing COVID-19 disease among these clinical trial participants with 11 cases of COVID-19 in the vaccine group and 185 in the placebo group developed infection with the SARS-CoV-2 virus. At the time of the analysis of these 196 COVID-19 cases, none in the vaccine group and 30 in the placebo group were classified as severe. 
Table 1: Dates of Approval of Various COVID-19 Vaccines in the United States.

\begin{tabular}{|c|c|c|c|}
\hline & \multicolumn{3}{|c|}{ Dates of Approval } \\
\hline & Pfizer/BioNTech & Moderna & Jansen \\
\hline \multicolumn{4}{|c|}{ Emergency Use Authorization } \\
\hline Adults & December $11,2020^{*}$ & December $18,2020^{* *}$ & February $27,2021^{* *}$ \\
\hline Adolescent (12-15 years) & May 10, 2021 & $\mathrm{~N} / \mathrm{A}$ & $\mathrm{N} / \mathrm{A}$ \\
\hline Children (5-11 years) & October 29, 2021 & $\mathrm{~N} / \mathrm{A}$ & $\mathrm{N} / \mathrm{A}$ \\
\hline Third Dose & August $12,2021^{* *}$ & August $12,2021^{* *}$ & $\mathrm{~N} / \mathrm{A}$ \\
\hline Booster Dose & September $22,2021^{* *}$ & October $20,2021^{* *}$ & October $20,2021^{* *}$ \\
\hline \multicolumn{4}{|c|}{ Full FDA Approval } \\
\hline Adults (> 16 years) & August 23, 2021 & N/A & $\mathrm{N} / \mathrm{A}$ \\
\hline
\end{tabular}

Note: *> 16 years

** $>18$ years

Table 2: COVID-19 Vaccination in the United States ${ }^{1}$.

\begin{tabular}{|c|c|c|c|c|}
\hline Vaccination & Total & $\mathbf{> 1 2}$ Years & $>$ >18 Years & $>$ (65 Years \\
\hline Fully Vaccinated & $193,832,584(58.4 \%)$ & $193,696,264(68.3 \%)$ & $180,989,020(70.1 \%)$ & $46,912,438(85.6 \%)$ \\
\hline At least One Dose & $222,629,671(67.4 \%)$ & $223,297,591(78.8 \%)$ & $208,233,040(80.6 \%)$ & $53,780,561(98.2 \%)$ \\
\hline Third Dose and Booster & $22,084,107(12.4 \%)$ & $24,054,828(13.3 \%)$ & $19,597,566(20.6 \%)$ & $14,297,960(30.5 \%)$ \\
\hline
\end{tabular}

Note: ${ }^{1}$ as of November 08,2021

Based on the data submitted to the FDA, the Moderna vaccine was approved under EUA for vaccination of adults ( $>18$ years of age) on December 18, 2020 [3]. The primary series of vaccination included two doses 28 days apart. Since its approval, over 70 million people have been fully vaccinated using the Moderna vaccine with no serious adverse effect. Based on the data related to the breakthrough infections in fully vaccinated people, on August 12, 2021, FDA authorized a third dose of Moderna vaccine in highrisk individuals and on October 20,2021, a single booster dose was authorized to be administered at least 6 months after completion of the primary series to individuals who fall into one of the following three categories; 65 years of age and older; 18 through 64 years of age at high risk of developing severe COVID-19; and 18 through 64 years of age with frequent institutional or occupational exposure to SARS-CoV-2 [4,5]. Since these approvals, over 5.9 million people have received an additional dose of the Moderna vaccine. Rare cases of myocarditis and pericarditis have been reported following vaccination after the second dose of both Pfizer/BioNTech and Moderna mRNA vaccines in adults, adolescents, and children [68]. Despite of these observations, both FDA and the U.S. Centers for Disease Control and Prevention (CDC) approved the use of Pfizer/BioNTech for adolescent and children. In June 2021, Moderna submitted data to the FDA requesting EUA for use of its vaccine in adolescent. According to a press release by Moderna, Inc., the "Phase 2/3 study of its COVID-19 vaccine (mRNA-1273) in adolescents has met its primary immunogenicity endpoint, successfully bridging immune responses to the adult vaccination. In the study, no cases of COVID-19 were observed in participants who had received two doses of the Moderna COVID-19 vaccine using the primary definition. In addition, a vaccine efficacy of $93 \%$ in seronegative participants was observed starting 14 days after the first dose using the secondary CDC case definition of COVID-19, which tested for milder disease. This study, known as the TeenCOVE study, enrolled more than 3,700 participants ages 12 to less than 18 years in the U.S" [9].

However, despite these observations, Scandinavian authorities suspended or discouraged the use of Moderna's COVID-19 vaccine in young people because of an increased risk of heart inflammation, a very rare side effect associated with the shot. Sweden suspended the use of Moderna for recipients under the age of 30 years and in Denmark, people under the age of 18 years will not be offered Moderna vaccine, and Norway recommended that those under the age of 30 years to get the Pfizer/BioNTech vaccine instead. Based on available data, FDA has delayed its approval of Moderna COVID-19 vaccine for adolescent suggesting that additional safety data will be required before any recommendation could be formulated. Similarly, on October 25, 2021, Moderna, Inc., also released interim data from the Phase 2/3 study, called the KidCOVE study, of mRNA1273 in children 6 to under 12 years of age. This interim analysis showed a robust neutralizing antibody response after two doses of mRNA-1273 at the 50 $\mu$ g dose level with a favorable safety profile [10]. Moderna plans to submit these data to the FDA and the 
European Medicines Agency (EMA) and other global regulators in the near term. At the recommendation of the FDA, Moderna, Inc., has however, agreed to delay submission of its request for an EUA for its mRNA vaccine for children 5-12 years of age. The need for further evaluation of clinical data by the FDA and the CDC to fully comprehend the cardiac side effects of Moderna mRNA vaccine in adolescent and children is important not only to ensure that it is safe but also to continue to sustain public confidence. The latter is critical in the face of unprecedented and unsubstantiated public resistance specifically for COVID-19 vaccination and to create a safe environment for children in the classrooms. However, based on the aforementioned information, it is our recommendation that both the FDA and the CDC must make every effort to conclude this evaluation process posthaste.

Our position has been supported by numerous leading scientific organizations who have co-signed a statement which states that "As physicians, nurses, public health, and health care professionals, and, for many of us, parents, we understand the significant interest many Americans have in the safety of the COVID-19 vaccines, especially for younger people. Today, the CDC Advisory Committee on Immunization Practices (ACIP) met to discuss the latest data on reports of mild cases of inflammation of the heart muscle and surrounding tissue called myocarditis and pericarditis following COVID-19 vaccination among younger people. The facts are clear: this is an extremely rare side effect, and only an exceedingly small number of people will experience it after vaccination. Importantly, for the young people who do, most cases are mild, and individuals recover often on their own or with minimal treatment. In addition, we know that myocarditis and pericarditis are much more common if you get COVID-19, and the risks to the heart from COVID-19 infection can be more severe" [11].

\section{Funding}

The project was funded by a Seed Grant from the DHR Health Institute for Research \& Development and the DHR Health.

\section{ISSN: 2574-1241}

DOI: 10.26717/BJSTR.2021.40.006391

Sohail Rao. Biomed J Sci \& Tech Res

This work is licensed under Creative

Commons Attribution 4.0 License

Submission Link: https://biomedres.us/submit-manuscript.php

\section{Conflict of Interest}

The authors have reported no conflict of interest.

\section{References}

1. (2021) COVID Data Tracker - Centers for Disease Control \& Prevention.

2. Baden LR, El Sahly HM, Essink B, Kotloff K, Frey S, et al. (2021) Efficacy and Safety of the mRNA-1273 SARS-CoV-2 Vaccine. The New England journal of Medicine 384(5): 403-416.

3. FDA Takes Additional Action in Fight Against COVID-19 By Issuing Emergency Use Authorization for Second COVID-19 Vaccine. Action Follows Thorough Evaluation of Available Safety, Effectiveness, and Manufacturing Quality Information by FDA Career Scientists, Input from Independent Experts.

4. (2020) Coronavirus (COVID-19) Update: FDA Authorizes Additional Vaccine Dose for Certain Immunocompromised Individuals. Other fully vaccinated individuals do not need an additional vaccine dose right now.

5. (2021) Coronavirus (COVID-19) Update: FDA Takes Additional Actions on the Use of a Booster Dose for COVID-19 Vaccines.

6. Kim HW, Jenista ER, Wendell DC, Azevedo CF, Campbell MJ, et al. (2021) Patients with Acute Myocarditis Following mRNA COVID-19 Vaccination. JAMA Cardiol 6(10): 1196-1201.

7. Dionne A, Sperotto F, Chamberlain S, Baker AL, Powell AJ, et al. (2021) Association of Myocarditis with BNT162b2 Messenger RNA COVID-19 Vaccine in a Case Series of Children. JAMA Cardiol e213471.

8. Das BB, Moskowitz WB, Taylor MB, Palmer A (2021) Myocarditis and Pericarditis Following mRNA COVID-19 Vaccination: What Do We Know So Far? Children (Basel) 8(7): 607.

9. (2021) Moderna Announces TeenCOVE Study of its COVID-19 Vaccine in Adolescents Meets Primary Endpoint and Plans to Submit Data to Regulators in Early June.

10. (2021) Moderna Announces Positive Top Line Data from Phase $2 / 3$ Study of COVID-19 Vaccine in Children 6 to 11 Years of Age.

11. (2021) American Academy of Pediatrics. Health Officials, AAP Urge COVID-19 Vaccination Despite Rare Myocarditis Cases. 2021. Health officials, AAP urge COVID-19 vaccination despite rare myocarditis cases | American Academy of Pediatrics (aappublications.org).

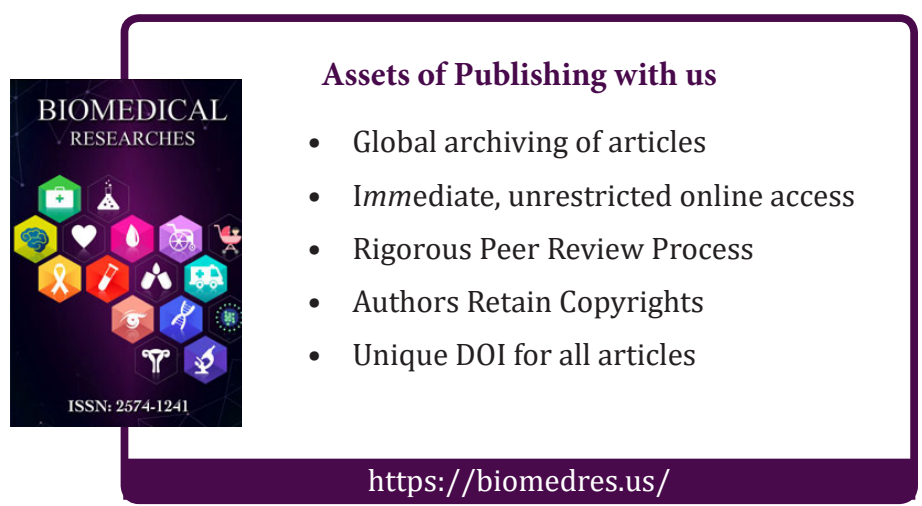

